\title{
Study on growth and accumulation characteristics of Sorghum
}

\section{bicolor $\times$ S.Sudanense. on uranium}

\author{
Zhang Shi-qi ${ }^{1, \text { a }}$, Wang Li-xing ${ }^{2, \text { b }}$, Hu Qing ${ }^{3, \text { c }}$, Zhang Peng ${ }^{4, ~ d}$, Rong Li-Shan ${ }^{\star 5, \text { e }}$ \\ ${ }^{1-5}$ Hunan Provincial Key Laboratory of Pollution Control and Resources Technology, University of \\ South China, Hengyang 421001, China) \\ aZsq_USC@126.com, ${ }^{\text {b3}} 358295987 @ q q . c o m,{ }^{c} 1508694748$ @qq.com, ${ }^{d} 1521400916 @ q q . c o m$, \\ e $148351409 @ q q . c o m$
}

Keywords: Sorghum bicolor $\times$ S.Sudanense. uranium growth accumulation characters

Abstract. It is utilized the pot experiments to investigate physiological and biochemical indexes as well as the characteristics of the accumulation of uranium of Sorghum bicolor $\times$ S.Sudanense. under the different uranium concentrations $(0,1,5,20 \mathrm{mg} / \mathrm{kg})$ stress. It shows that photosynthetic pigment and soluble protein content increased under the low uranium concentration stress, but with the increasing of uranium concentration, the high uranium concentration inhibits the synthesis of photosynthetic pigments and soluble proteins. Uranium stress leads to the content of MDA in Sorghum bicolor $\times$ S.Sudanense. increased gradually. The enrichment of uranium in Sorghum bicolor $\times$ S.Sudanense. increased with the increase of the concentration of uranium, and the enrichment in the shoots was higher than that in the roots. The translation coefficient of Sorghum bicolor $\times$ S.Sudanense. shows the current which is first up and then down. It is of good enrichment ability of Sorghum bicolor $\times$ S.Sudanense..

\section{Introduction}

With the rapid development of China's nuclear power industry, uranium mining has caused the environment to varying degrees of radioactive pollution ${ }^{[1]}$. The contamination of natural water and soil with surface runoff and underground percolation is very harmful to the ecological environment and human health ${ }^{[2-4]}$. In summary, the restoration of soil contaminated by uranium is imminent.

Soil remediation refers to the transfer, absorption, degradation and transformation of pollutions in soil by some methods to get an acceptable level, or to be transformed into harmless substances. Traditional physical and chemical remediation method is expensive, only for a small area of heavily polluted soil, and may lead to the damage of soil structure, soil biological activity decreased and soil fertility degradation ${ }^{[5]}$. Phytoremediation refers to a new treatment technology that uses plants in the original location and their rhizosphere microorganisms to remove pollutions in the soil ${ }^{[6]}$. It is low cost, less investment, easy operation, lasting effect, environmental aesthetics and governance [7]. Moreover, planting on contaminated land has the effect of greening and beautifying the environment and is considered to be a promising technology for remediation of radioactive contaminated soil ${ }^{[8]}$. Zhao Ying's pot experiment shows that the hybrid Pennisetum, Sorghum bicolor $\times$ S.Sudanense., Sultan grass on the PAHs and as combined pollution in soil removal ${ }^{[9]}$. Wan Qin-fang's study shows that several plants such as Ophiopogon in Sichuan can be used as uranium hyper accumulator, which enriched the uranium up to $1.67 \mathrm{x} 103 \mathrm{mg} / \mathrm{kg}^{[10]}$. Zhu Ye-an's screening tests shows that content of uranium enriched in white radish by citric acid (the total uranium $280 \mathrm{mg} / \mathrm{kg}$ in the soil) is $323.734 \mathrm{mg} / \mathrm{kg}^{[11]}$. Jia Wenfu's pot experiment shows that the okra had 
strong resistance to uranium and the ability to enrich it ${ }^{[12]}$.

At present, the study on the adaptability of a certain plant in the soil environment with different uranium concentrations and the biochemical indexes of plants under uranium stress need to be studied. Therefore, this paper uses Sorghum bicolor $\times$ S.Sudanense. as a test plant and uses pot experiments to investigate the physiological and biochemical responses of Sorghum bicolor $\times$ S. Sudanense. under different uranium concentrations and the effect on uranium enrichment.

\section{Material and Methods}

\section{Test material}

The river sand and vermiculite was purchased by the test soil in the market and uncontaminated soil around a tailings reservoir with volume ratio of 1:1:1. Test plant materials is Sorghum bicolor $\times$ S.Sudanense, whose seeds were purchase in the seed market. The sprouting test showed that the germination rate of the seed of Sorghum bicolor $\times$ S.Sudanense. was over $75 \%$.

\section{Plant culture, uranium contaminated soil preparation and plant collection}

Plants are planted in a pot under natural conditions outside (a canopy to prevent rain), and each basin $(150 \mathrm{~mm} \times 190 \mathrm{~mm}$ specification plastic flowerpot) equips test soil $1.0 \mathrm{~kg}$. First, spray $\mathrm{UO}_{2}\left(\mathrm{NO}_{3}\right)_{2} \bullet 6 \mathrm{H}_{2} \mathrm{O}$ solution uniformly into the soil and then fully stir evenly. The uranium solution was prepared with uranium standard reserve solution, and the soil uranium concentration was 1, 5, $20 \mathrm{mg} / \mathrm{kg}$, respectively ${ }^{[13]}$. After a week, the seeds were soaked in $75 \%$ ethanol for 3 minutes, and 3 times were washed with aseptic water. Water 1 2 times a day with an improved Hoagland 's nutrient solution once a week. 3 parallel tests were conducted in each group, and the plants with a no uranium were selected as the control group. Plants are harvested in uranium contaminated soil for 60 days.

\section{Determination method}

Determination of photosynthetic pigments (including chlorophyll a, chlorophyll $\mathrm{b}$ and carotenoids) refers to reference ${ }^{[14]}$. Determination of the content of malondialdehyde (MDA) was tested by thiobarbituric acid method ${ }^{[13]}$, and soluble protein content was tested by Coomassie brilliant blue method ${ }^{[14]}$. The determination of uranium content in plant samples is carried out in accordance with the standard (EJ267.4-1984) and the TRPO-5-Br-PADAP spectrophotometric method was used to determine the uranium concentration. All data are processed by Graph Pad Prism 5.

\section{Results and Discussions}

\section{Effects of uranium on photosynthetic pigments of Sorghum bicolor $\times$ S.Sudanense.}

Photosynthetic pigments are the material basis of photosynthesis in plants. Environmental stress can lead to the destruction and degradation of photosynthetic pigments ${ }^{[15]}$. Chlorophyll is the main pigment of photosynthesis in plants. The change of chlorophyll content can not only reflect the function of photosynthesis, but also indicate the senescence of plant tissues and organs under stress ${ }^{[16]}$. From Fig.1, as the concentration of uranium increased gradually, the content of chlorophyll a, chlorophyll $\mathrm{b}$ and carotenoid increased. When the concentration of uranium in the soil was $1 \mathrm{mg} / \mathrm{kg}$ and $5 \mathrm{mg} / \mathrm{kg}$, photosynthetic pigments content in the leaves increased slightly compared with the control group. When the uranium concentration in soil was $20 \mathrm{mg} / \mathrm{kg}$, the contents of chlorophyll a, chlorophyll $\mathrm{b}$ and carotenoids in leaves decreased. However, there was no obvious yellowing or dead phenomenon of Sorghum bicolor $\times$ S. Sudanense. during the test. 


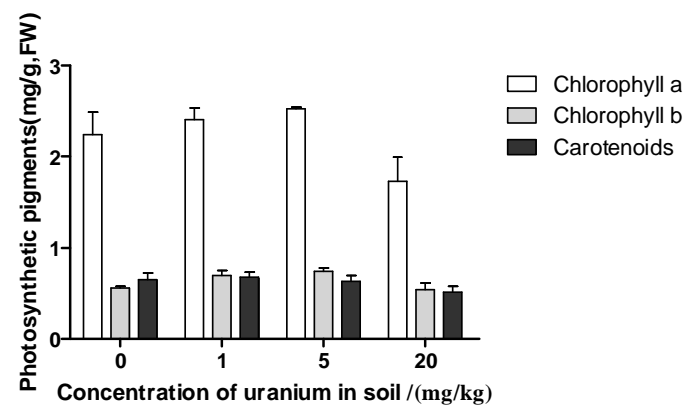

Fig.1 Effects of uranium stress on the content of photosynthetic pigments in Sorghum bicolor $\times$ S. Sudanense.

\section{The effect of uranium on MDA}

Plant organs are damaged by aging or under adverse circumstances. Malondialdehyde (MDA) is one of the most important products of membrane lipid peroxidation. Its content can reflect the degree of membrane lipid peroxidation and the degree of stress injury ${ }^{[17]}$. From Fig.2, MDA content in Sorghum bicolor $\times$ S.Sudanense. increased with the increase of uranium concentration in the soil. It shows that uranium has a very significant effect on the MDA of Sorghum bicolor $\times$ S.Sudanense. When the concentration of uranium stress is $20 \mathrm{mg} / \mathrm{kg}$, the stem and leaf is 2.73 times as high as that of the control group, and the content of MDA in the root is 3.89 times as that of the control group.

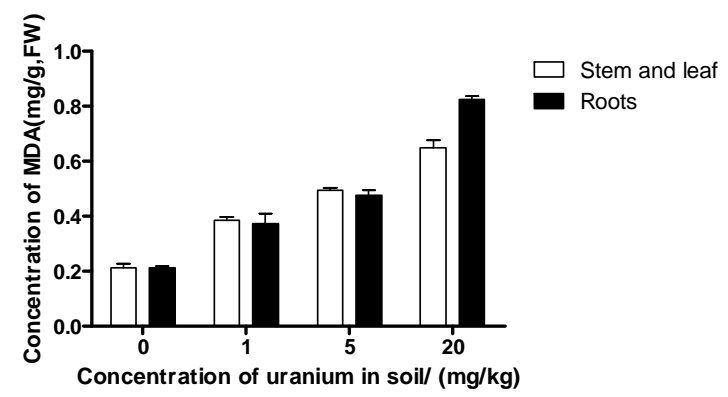

Fig. 2 Effect of uranium stress on the content of MDA in Sorghum bicolor $\times$ S. Sudanense.

\section{Effect of uranium on soluble protein of Sorghum bicolor $\times$ S.Sudanense.}

The content of soluble protein in plants is an important physiological and biochemical index for the growth and development of plants under stress. Therefore, soluble protein content is an important indicator to measure the stress of heavy metals in plants. From Fig.3, the soluble protein content in the stem and leaf increased firstly and then decreased with the increase of uranium concentration in the soil. When the concentration of uranium stress was $5 \mathrm{mg} / \mathrm{kg}$, the soluble protein content in the stem and leaf was the highest, and the content was about $142.72 \%$ of the control group. However, the soluble protein in the root decreased first and then increased. Moreover, the soluble protein content in the root was lower than that of the control group when the concentration of uranium was $20 \mathrm{mg} / \mathrm{kg}$.

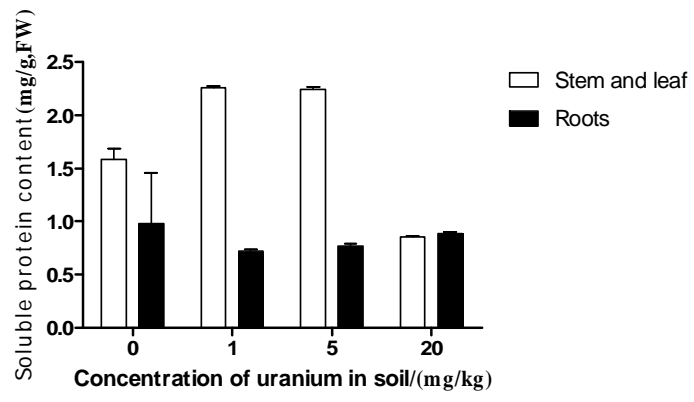

Fig.3 Effect of uranium stress on soluble protein content of Sorghum bicolor $\times$ S. Sudanense. 


\section{Enrichment effect of Sorghum bicolor $\times$ S.Sudanense. on uranium}

From Fig.4, the uranium content in stems and leaves and roots increased with the increase of uranium concentration in soil. This indicates that the bioaccumulation of uranium by Sorghum bicolor $\times$ S.Sudanense. increased with the increase of uranium concentration in soil. When the concentration of uranium in soil was $20 \mathrm{mg} / \mathrm{kg}$, the stem and the uranium content in root reached the maximum value, the uranium content in stem and leaf and roots was $255.81 \mathrm{mg} / \mathrm{kg}$ and $1479.01 \mathrm{mg} / \mathrm{kg}$ respectively. It is clear that even under different uranium concentration treatments, the content of uranium in roots is much larger than that in its stem and leaf.

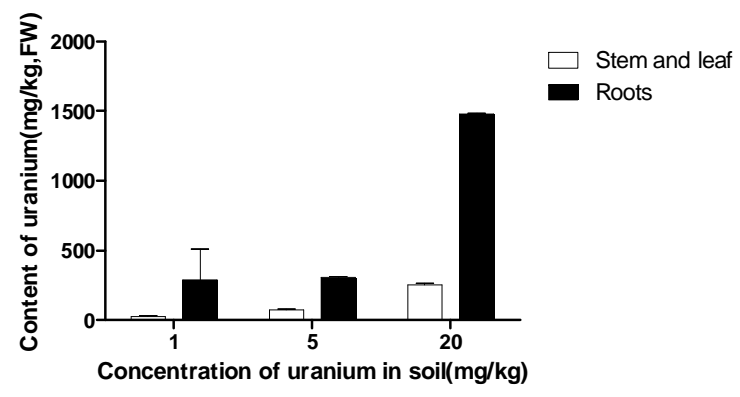

Fig.4 Uranium content in the parts and roots of the stems and leaves of Sorghum bicolor $\times$ S. Sudanense.

\section{Bioaccumulation and transport coefficient of Sorghum bicolor $\times$ S.Sudanense.}

According to the calculation formula of the biologic enrichment coefficient (BCF) of uranium and calculation formula of plant transport coefficient, the results is shown in Table 1.

Table 1 Enrichment and transport coefficient of uranyl to uranium

\begin{tabular}{|c|c|c|c|}
\hline \multirow{2}{*}{$\begin{array}{c}\text { Uranium treatment } \\
\text { concentration / } \\
(\mathrm{mg} / \mathrm{kg})\end{array}$} & \multicolumn{2}{|c|}{ Enrichment / $(\mathrm{mg} / \mathrm{kg})$} & \multirow{2}{*}{ Transport coefficient /\% } \\
\cline { 2 - 3 } & Stems and leaves & Roots & \\
\hline 0 & 0 & 0 & 0 \\
\hline 5 & 24.4292 & 288.3670 & 8.47 \\
\hline 15 & 75.5895 & 305.8107 & 24.72 \\
\hline 20 & 255.8131 & 1479.0087 & 17.30 \\
\hline
\end{tabular}

From table 1, the transfer coefficient of uranyl showed a tendency to increase first and then decrease. In addition, with the increase of uranium concentration, the enrichment of the stems and leaves and roots increased, thus reflecting the stronger enrichment ability of Sorghum bicolor $\times$ S.Sudanense. on uranium.

\section{Conclusions}

(1) The photosynthetic pigment and soluble protein content were increased under low concentration of uranium. However, with the gradual increase of uranium concentration, the toxic effect of uranium on the Sorghum bicolor $\times$ S.Sudanense. is obvious, resulting in the decrease of photosynthetic pigment and soluble protein content. That is, high concentration of uranium inhibits the synthesis of photosynthetic pigments and soluble proteins.

(2) Uranium stress leads to high MDA content in Sorghum bicolor $\times$ S.Sudanense, and the effect of uranium on the MDA was very significant. The enrichment of uranium is increased with the increase of uranium concentration, and the enrichment capacity of uranium is very strong on both stems and leaves and roots. 
(3) The transfer coefficient of uranyl to uranium increases first and then decreases, and the enrichment ability of Sorghum bicolor $\times$ S. Sudanense. to uranium is strong.

\section{Acknowledgement}

This work was financially supported by Innovation Platform Open Fundation of Hunan Province (16K075) and Research study and innovative experiment program for College Students (2016NH004XJXZ)

\section{References}

[1]Yao Tianyue, Wang Dan, Li Zehua, Long Chan, Jiang Wenjing, Chen Li, Xiang Mingwen. Study on the enrichment of uranium in soil by 8 species of flower plants [J]. Environmental Science and technology (2016)

[2]Hu Kaiguang, Liu Zenggang. Study on the adsorption of uranium containing wastewater by modified bagasse [J]. Journal of University of South China (NATURAL SCIENCE EDITION) (2016)

[3] Phillipsa D H, Gub B, Watsonb D B, et al. Uranium removal from contaminated groundwater by synthetic resins [J]. Water Research (2008)

[4] Gadd G M. Biosorption: critical review of scientific rationale, environmental importance and significance for pollution treatment. Journal of Chemical Technology and Biotechnology (2009)

[5] Zhao Siyan. Current situation and treatment method of heavy metal pollution in urban soil [J]. Henan science and technology (2013)

[6] Wang J L, Chen C. Biosorption of heavy metals by Saccharomyces cervisiae: A review [J]. Biotechnol Advances (2006)

[7]Bao Tong, Lian Mei, Sun Lina, Sun Tieheng, Su Lei, ray Kong. Research Progress on Phytoremediation of heavy metal contaminated soil [J]. Ecological Environment (2008)

[8]Du Liang, Li Ye, Wang Ping and so on. Research Progress on bioremediation of contaminated soil [J]. Environmental Engineering (2013)

[9]Zhao Ying, Liu Lijun, the party Jin Hua and so on. Study on Phytoremediation of contaminated soil in polluted irrigated area [J]. Journal of ecological environment (2013)

[10] Wan Qinfang, Ren Min Min, Wang Liang and so on. Study on Phytoremediation of uranium contaminated soil [J]. Journal of Chemistry (2011)

[11] Zhu ye'an. Study on heavy metal pollution and Accumulative Characteristics of uranium enriched plants in uranium mining area [D]. Institute of Technology in East China (2013)

[12] Jia Wenfu, Luo Xuegang, Chen Gongliang, Wang Jia, He Xiuhong. Photosynthetic physiological response and absorption characteristics of okra to uranium stress [J]. Environmental Science and technology (2015)

[13] Yan Zheng, Xie Shuibo, Li Shiyou. Water hyacinth, Pistia stratiotes on uranium stress physiological and biochemical response [J]. Journal of Safety and Environment (2012)

[14] Wang Xuekui. Principles and techniques of plant physiological and biochemical experiments [M]. Higher Education Press (2006)

[15] Mishra, V.K. and B. Tripathi, Concurrent removal and accumulation of heavy metals by the three aquatic macrophytes [J]. Bioresource technology (2008)

[16] Jennifer Cutraro, Nora Goldstein. Cleaning up contaminants with plants[J]. Biocycle (2005)

[17] R.K. and S.K. Panda, Copper-induced growth inhibition, oxidative stress and ultrastructural alterations in freshly grown water lettuce (Pistia stratiotes L.) [J]. Comptes rendus biologies (2009) 